\title{
Alfabetização de crianças de seis anos e a ampliação do Ensino Fundamental: um estudo de caso ${ }^{1}$
}

\author{
Maria do Socorro Macedo ${ }^{2}$ \\ socorronunesmacedoufsj@gmail.com
}

Ana Caroline Almeida ${ }^{3}$

karolyne_jv@hotmail.com

\section{Resumo}

Neste texto buscamos compreender como tem se dado a alfabetização das crianças de seis anos do Ensino Fundamental (EF) em turmas, nas quais, subentende-se, já se consolidou o ordenamento legal que trata da ampliação do EF. Optamos pela perspectiva etnográfica como aporte teórico-metodológico da investigação. Os dados da sala de aula foram coletados numa turma de uma escola pública da Rede Municipal de Tiradentes, em Minas Gerais, entre abril e dezembro de 2010, com um total de 47 dias observados e registrados no caderno de campo, além de entrevista com a professora. Os resultados indicam que a concepção de alfabetização presente nessa prática se vincula a uma visão da escrita apenas como um código de transcrição das unidades sonoras em unidades gráficas, uma vez que as atividades predominantes na sala de aula eram cópia de textos curtos, repetição de palavras soltas, decodificação de sílaba por sílaba.

Palavras-Chave: letramento; alfabetização; etnografia; ampliação do Ensino Fundamental.

1 Texto apresentado na 35a Reunião Anual da ANPED, realizada em 2012.

2 Doutora em Educação pela UFMG. Professora do Programa de Pós-Graduação em Educação da Universidade Federal de Sao João del-Rei (UFSJ), MG.

3 Mestre em Educação pela Universidade Federal de Sao João del-rei (UFSJ). Professora da Rede Municipal de Tiradentes, Minas Gerais. 


\title{
Literacy in elementary school: a case study
}

\begin{abstract}
This paper aims to understand the teaching-learning process of literacy in a six years children classroom in which has already consolidated the legal system that deals with the expansion of the Fundamental School. We chose the ethnographic perspective as the theoretical and methodological research we conducted in a class of children six years of a public school in Minas Gerais. The data were collected between April and December 2010, a total of 47 days observed and recorded in a field book, and interview with the teacher. The results indicate that the pedagogical practice is connected with a vision of literacy as a neutral code reduced to sound and graphic units, since the predominant activities in the classroom were copies of short texts, repeat single words, syllable by syllable decoding.
\end{abstract}

Keywords: literacy; ethnography; elementary school.

\section{Introdução}

Uma das mudanças políticas mais recentes que afeta diretamente a organização e estruturação do ensino no Brasil se refere à ampliação da escolaridade obrigatória de oito para nove anos, com a inclusão da criança de seis anos no Ensino Fundamental (EF), em decorrência da Lei n. 11.274 (BRASIL, 2006). Cabe ressaltar que Minas Gerais se antecipou a essa Lei e passou a atender às crianças de seis anos no EF já a partir de 2004, na chamada Fase Introdutória. Para Santos e Vieira (2006), em MG esse aumento se deu com a intenção manifesta de repensar a cultura pedagógica da alfabetização no EF e reverter resultados negativos evidenciados nas avaliações do Sistema Mineiro de Avaliação da Educação Pública (SIMAVE) e do Sistema Nacional de Avaliação da Educação Básica (SAEB).

Assim, o contexto atual coloca em discussão alguns aspectos da escolarização inicial, como a organização curricular para essas crianças, a questão de como o tempo e o espaço são utilizados nas instituições de 
ensino, o lugar do lúdico nas práticas pedagógicas, a alfabetização e o letramento. E foi exatamente esse último aspecto o foco de uma pesquisa de mestrado, de caráter etnográfico, que realizamos em 2010, na qual temos como objetivo apresentar e analisar práticas alfabetizadoras com crianças de seis anos no EF, em Tiradentes, um município mineiro.

A ideia foi conhecer e analisar como os professores do primeiro ano desse município se apropriaram da política de ampliação do EF e que concepções de alfabetização e letramento embasam seus discursos e práticas. Assim, buscamos compreender como tem se dado a alfabetização dessas crianças de seis anos no EF em turmas, nas quais, subentende-se, já se consolidou o ordenamento legal que trata da ampliação do EF. Em forma de pergunta: De que modo as proposições teórico-metodológicas em torno do EF de nove anos, da alfabetização e do letramento, têm influenciado a prática dos professores?

Neste texto, um recorte desse estudo mais amplo, centramos as discussões em torno dos aspectos observados numa das turmas de $1^{\mathrm{o}}$ ano do município no que se refere especificamente ao trabalho em torno da leitura e da escrita, buscando evidenciar as práticas recorrentes nessa turma e a forma como a leitura e a escrita são ensinadas. Para tanto, está organizado em três seções. Na primeira, apontamos de forma breve a discussão da educação como um direito, princípio que subjaz a normatização da ampliação do EF. Na segunda parte, justificamos a perspectiva etnográfica como opção teórico-metodológica adotada para o estudo. E, na terceira, apresentamos e discutimos práticas observadas ao longo do período de imersão na sala de aula, buscando desvelar a concepção de alfabetização e letramento que fundamenta as escolhas feitas pela professora regente da turma.

\section{A educação como direito}

Para autores como Cruvinel (2009) e Flash (2009), é necessário discutir a ampliação da escolaridade obrigatória no Brasil como um avanço, de fato, na conquista da cidadania. Uma conquista que impõe novos desafios estruturais para a área educacional e, sobretudo, pedagógicos, pois é no âmbito das práticas pedagógicas que esse direito pode ser legitimado. 
É sabido que a escola, como equipamento cultural, vincula-se ao Estado, que, por sua vez, procura assegurar seu funcionamento e se esforça por universalizá-la. Desde a consolidação da república brasileira, o Estado é tido como responsável imediato pelas ações referentes à educação pública, o que foi assegurado já na Constituição de 1934, que afirmou que a educação é direito de todos e deve ser ministrada pela família e pelos poderes públicos.

Na atual Constituição Federal (CF/1988), do art. 205 ao art. 214, o item Educação é tratado de modo especial. O art. 205 e o art. 206 merecem destaque, pois estabelecem a Educação como direito de todos e dever do Estado, visando ao pleno desenvolvimento da pessoa, seu preparo para o exercício da cidadania e sua qualificação para o trabalho. Declara como princípios do ensino não só a igualdade de condições de acesso e permanência na escola, mas a liberdade, o pluralismo de ideias, a gratuidade do ensino, a valorização dos profissionais da educação, a gestão democrática e a garantia de um padrão de qualidade.

O ingresso das crianças de seis anos no EF é uma política afirmativa que traz em seu bojo a ideia da inclusão, na qual os maiores beneficiados seriam as crianças das camadas populares, que, por inúmeros motivos, boa parte ainda se encontra fora da sala de aula. No entanto, essa política nos leva a olhar para a escola pública brasileira na atualidade e pensar como esses princípios do ensino, assegurados pela $\mathrm{CF}$, principalmente $\mathrm{o}$ que trata da garantia de um padrão de qualidade, podem ser garantidos.

De acordo com o Ministério da Educação (BRASIL 2007; 2009), são objetivos da ampliação do tempo na escolaridade obrigatória para nove anos: possibilitar a qualificação do ensino e da aprendizagem da alfabetização e do letramento, oferecer maiores oportunidades de aprendizagem no período de escolarização obrigatória e assegurar que, ingressando mais cedo nos sistemas de ensino, as crianças prossigam nos estudos, alcançando maior nível de escolaridade. Ou seja, a transição, ou o ingresso da criança de seis anos no EF, constituiu um novo fenômeno social, que tem sido alvo de discussões entre diversos estudiosos, uma vez que implantar um EF de nove anos com qualidade requer, entre outros aspectos, uma reorganização pedagógico-curricular tanto do EF 
como da Educação Infantil.

Pesquisas atuais, como as de Araújo (2008), Bonfim (2010) e Dantas (2009), revelam, entre outros aspectos, o desconhecimento da política por parte dos professores, o que tem acarretado práticas pedagógicas no $1^{\circ}$ ano centralizadas nos processos de alfabetização, com pouco espaço destinado ao lúdico e à brincadeira, atividades próprias dessa faixa etária.

Desse modo, a centralidade do trabalho na alfabetização, a partir da nova configuração do EF, volta a colocar nas pautas de discussão esse complexo fenômeno. Para Mortatti (2004, p. 15), "é dever do Estado proporcionar, por meio da educação, o acesso de todos os cidadãos ao direito de aprender a ler e a escrever, como uma das formas de inclusão social, cultural e política e de construção da democracia". No entanto, no Brasil, tem sido um desafio para que se efetivem plenamente esse dever do Estado e direito do cidadão.

No entanto, o problema da alfabetização e a correlação entre a persistência do analfabetismo, do fracasso escolar e de desenvolvimento da nação continuam sendo objeto de diferentes explicações e tentativas de solução, seja por meio de políticas públicas, de iniciativas mais localizadas ou não governamentais. Essas tentativas de solução vêm focalizando ora os métodos de ensino da leitura e escrita, ora a formação do professor, ora os processos cognitivos dos alunos, ora a estrutura e funcionamento do sistema de ensino (MORTATTI, 2004). Nessa direção, compreendemos que a política de ampliação da escolaridade obrigatória para nove anos representa uma dessas tentativas, sobretudo de melhorar a qualidade da alfabetização no Brasil, conforme apontado nos documentos oficiais que constituem a base da proposta.

\section{A perspectiva etnográfica}

Consideramos que é no âmbito das práticas pedagógicas que poderemos observar o impacto dessa política pública de ampliação do Ensino Fundamental, com o foco nas práticas de alfabetização e letramento. A expansão das vagas se configura apenas como um primeiro passo na direção de se investir na educação do País. Para que o direito à educação seja de fato legitimado, a criança deve ser a protagonista de 
todo o processo nas instituições educativas, considerando-se as diversas dimensões de sua formação, em que uma das mais importantes é o desenvolvimento da linguagem escrita. Por isso, optamos pela perspectiva etnográfica dos estudos sobre letramento como o principal aporte teórico-metodológico da investigação que realizamos, uma vez que essa perspectiva nos permite conhecer as práticas pedagógicas vivenciadas na sala de aula, buscando compreender a lógica constitutiva de tais práticas.

Importante ressaltar que não se trata de uma etnografia no sentido estrito do termo, do pesquisador-etnógrafo, apesar de utilizarmos as ferramentas e estratégias do trabalho etnográfico. Trata-se, sim, de considerar a etnografia como uma lógica de investigação na área educacional, um conjunto de princípios que localizam a etnografia dentro de teorias sobre cultura aplicadas em pesquisas no campo da educação, conforme apontado no trabalho de Green, Dixon e Zaharlich (2005).

Green, Dixon e Zaharlich (2005) defendem que já existe um conjunto considerável de pesquisas na interface entre etnografia e educação, com um conjunto de conceitos, práticas e ações, o qual possibilita entender a etnografia como uma abordagem de pesquisa para o campo da educação. Para elas, três princípios-chave dão base à etnografia e são constituintes de uma lógica de investigação de pesquisas fundamentadas na antropologia cultural e na etnografia da comunicação: a etnografia como o estudo de práticas culturais, como uma perspectiva contrastiva e como uma perspectiva holística.

Esses princípios, grosso modo, buscam compreender os padrões culturais e as práticas das vidas cotidianas, dar visibilidade aos princípios de práticas comumente invisíveis que norteiam as ações, interações, produção de artefatos e construção de eventos e atividades da vida diária dos membros de um grupo e entender as relações entre parte-todo nesse contexto, a partir de uma perspectiva êmica, ou de um membro da comunidade.

Desse modo, compreendemos a sala de aula como uma comunidade cultural, com diferentes sujeitos, assumindo papéis também distintos no processo de ensino-aprendizagem (CASTANHEIRA, 2000 apud MACEDO, 2005). Cultura é entendida aqui como "um conjunto e princípios de práticas que são construídos por seus membros à medida que estabelecem papéis e relações, normas e expectativas, e direitos e 
obrigações que constituem o sentimento de pertencimento ao grupo local", e ao pesquisador cabe "revelar as maneiras pelas quais os membros do grupo estudado percebem sua realidade e seu mundo, como eles constroem seus padrões de vida, e como, por intermédio de suas ações e interações, constituem seus valores, crenças, ideias e sistemas simbólicos significativos" (GREEN; DIXON; ZAHARLICH, 2005, p. 30).

O estudo de caso, de cunho etnográfico, possibilitou-nos investigar ações de letramento em um contexto específico: uma turma de $1^{\circ}$ ano com crianças de seis anos no EF. A opção por essa perspectiva nos fez ir além da mera descrição das atividades cotidianas realizadas pelos sujeitos, professora e alunos, e propiciou-nos "o conhecimento de como os participantes utilizam tempo e espaço na sala de aula (CASTANHEIRA; GREEN; DIXON, 2007, p. 12). Observar o que de fato acontece no interior dessas turmas fornece subsídios importantes para fomentar o debate em torno da problemática da ampliação do tempo no EF.

Os dados foram coletados entre abril e dezembro de 2010, com um total de 47 dias observados e registrados no caderno de campo. Além disso, realizamos entrevista com a professora da turma a fim de compreender aspectos de sua prática pedagógica observados em sala de aula. Ao longo do processo, a frequência de visitas à turma foi intensa, principalmente nos meses observados no primeiro semestre - maio, junho e julho. As observações se encerraram no mês de novembro, com um total de 47 dias registrados em notas de campo, o que corresponde, aproximadamente, a 228 horas de observação.

A escola observada é formada pelas classes média e média baixa, filhos de trabalhadores da construção civil, domésticas, diaristas, pequenos comerciantes, funcionários públicos municipais, autônomos e desempregados. De acordo com o projeto político-pedagógico (PPP) da escola, é uma população cujo grau de escolaridade dos pais ainda é baixo - EF incompleto -, com pouco acesso a bens culturais, a eventos que ocorrem na cidade, como a Mostra de Cinema e o Festival de Gastronomia. Contudo, preservam-se algumas tradições e costumes locais, como as festas juninas. A maioria das famílias, constituídas de, no mínimo, três e, no máximo, oito pessoas, possui casa própria, infraestrutura adequada e saneamento básico, embora as construções sejam humildes. 
O quadro de pessoal era formado por 16 professoras, sendo duas eventuais, uma assistente educacional, uma diretora, uma vice-diretora, duas coordenadoras pedagógicas (uma por turno) e oito serventes.

A estrutura física da escola, uma construção antiga, datada do século XIX, foi adaptada para uso escolar. Atualmente, é composta por sete salas de aula, um laboratório de informática com 24 computadores ligados à internet e uma sala para as Mesas Pedagógicas, onde funciona também a sala de vídeo. A escola conta ainda com seis banheiros, sendo três para meninas, dois para meninos e um para as professoras, pia para a escovação de dentes, um bebedouro, inadequado para crianças menores, um pátio interno, uma quadra e um parquinho desativado.

A turma observada é composta por 22 alunos com idades variadas. Nove deles já tinham seis anos completos no início das observações e fariam sete anos no segundo semestre de 2010. Os outros 13 estavam com cinco anos, mas fariam seis anos de idade ainda no primeiro semestre de 2010. Isso se deve à data corte da matrícula no EF, que, para o ano de 2010, ainda possibilitou o ingresso de crianças com seis anos a completar até 30 de junho do ano letivo. Em conversa informal com a professora no início do período de observação, ela afirmou que alguns poucos alunos já estavam alfabetizados, ou seja, sabiam ler e escrever; mas a maioria ainda se encontrava nesse processo.

Na próxima seção, destacamos as principais práticas relacionadas à leitura e à escrita, que foram observadas na turma ao longo do ano, a fim de contribuir para as discussões em torno dos processos de alfabetização e letramento na configuração atual do EF.

\section{Situações de alfabetização e letramento no cotidiano de uma turma de $1^{\circ}$ ano}

Atualmente, há um consenso de que a alfabetização precisa ocorrer na perspectiva do letramento. Conforme indicado por Rojo (2009, p. 107), "um dos objetivos principais da escola é justamente possibilitar que seus alunos possam participar das várias práticas sociais que se utilizam da leitura e da escrita (letramentos) na vida da cidade, de maneira ética, crítica e democrática". Desse modo, "o letramento escolar tal como o 
conhecemos, voltado principalmente para as práticas de leitura e escrita de textos em gêneros escolares [...] e para alguns gêneros escolarizados advindos de outros contextos" (p. 108), não será suficiente.

Compreendemos o termo letramento, sobretudo, como uma prática social e culturalmente determinada, constituída nas e pelas relações de poder que se estabelecem cotidianamente (STREET, 1984). Nessa mesma perspectiva, Castanheira, Green e Dixon (2007, p. 8) afirmam que:

[...] quando professores e estudantes constroem as normas e as expectativas, os papéis e as relações, os direitos e os deveres que orientam sua participação na vida cotidiana na sala de aula, estão também definindo o que significa letramento e ação letrada nos eventos locais da sala de aula.

As autoras indicam ainda que não há uma definição única para o termo letramento, mas que esse termo adquire um ou outro significado dependendo de cada grupo em questão. A sala de aula pode ser considerada, portanto, como uma comunidade que utiliza a leitura e a escrita em situações específicas e que, nesse contexto, o letramento também adquire um significado específico.

A compreensão do termo letramento, com um foco mais social, perpassando os usos e as práticas de linguagem que envolvem a escrita de formas variadas e em contextos também distintos (família, escola, igreja etc.) se deu a partir dos Novos Estudos sobre Letramento (NLS), que, numa perspectiva etnográfica e antropológica, discutem duas concepções de letramento: o letramento autônomo e o letramento ideológico (STREET, 1984; 1993; 2001; 2003).

Para Street (1993, p. 5), o modelo autônomo vê o letramento "em termos técnicos, tratando-o como independente do contexto social, uma variável autônoma cujas consequências para a sociedade e a cognição são derivadas de sua natureza intrínseca". Ou seja, essa concepção vinculase, numa relação causal, ao progresso, à civilização, à mobilidade social.

Ao contrário do modelo autônomo, o modelo ideológico contraposto porStreet (1993, p.7), "vêas práticas de letramento como indissoluvelmente ligadas às estruturas culturais e de poder da sociedade e reconhece a variedade de práticas culturais associadas à leitura e à escrita em diferentes contextos". Ou seja, as práticas de letramento são cultural e 
socialmente determinadas, construídas em contextos específicos de uso da escrita, extrapolando a ideia da relação causal com o progresso e a mobilidade social, proposta pelo modelo anterior.

Para Rojo (2009, p. 99):

[...] o significado do letramento varia através dos tempos e das culturas e dentro de uma mesma cultura. Por isso, práticas tão diferentes, em contextos tão diferenciados, são vistas como letramento, embora diferentemente valorizadas e designando, a seus participantes, poderes também diversos.

É nesse questionamento da escrita como objeto universal e neutro que surge a ideia dos múltiplos letramentos. As práticas de letramento são sociais e, portanto, não podem ser compreendidas fora dos seus contextos políticos e ideológicos.

Para Street (2003, p. 78):

[...] engajar-se em práticas de letramento é sempre um ato social. [...] As formas nas quais professores e estudantes interagem já são uma prática social que afeta a natureza do letramento que está sendo aprendido, as ideias sobre letramento apropriadas pelos participantes e sua posição nas relações de poder.

Assim, mesmo usando a leitura e a escrita de modos específicos, a escola constrói um tipo de letramento, a saber: o letramento escolar. A respeito do letramento escolar, Macedo (2010) sustenta que a sala de aula, espaço privilegiado para a construção desse tipo de letramento, pode ser entendida como um espaço de tensões entre os modelos autônomo e ideológico de letramento.

A seguir, destacamos e analisamos as práticas que envolveram a leitura e a escrita nessa turma e foram recorrentes na rotina observada ao longo do ano escolar. Tais práticas revelam a lógica de organização pedagógica do trabalho da professora no ensino da leitura e escrita. Somente pela permanência ao longo do ano nessa sala de aula, numa perspectiva etnográfica, foi possível identificar e compreender como esta lógica se dá, como é construída pelos sujeitos na sala de aula. São elas: a cópia do calendário e de pequenos textos; atividades de leitura e atividades de sistematização do código. 


\section{A cópia do calendário e de pequenos textos}

A cópia do calendário se iniciava quando a professora registrava no quadro a saudação "Boa tarde!" e, logo em seguida, a data do dia por extenso. Nesse momento, ela costumava interagir com os alunos, conversando sobre o dia da semana em que estavam, quais são os anteriores e os posteriores a ele. A data também era discutida com os alunos, tomando como referência o dia em questão ou o dia anterior, quando ela aproveitava para trabalhar a distribuição dos meses ao longo do ano e dos dias ao longo do mês.

Abaixo da data, eram registradas outras coisas que foram aumentando conforme o decorrer do ano. No começo, ela registrava só o alfabeto, em letras de forma maiúscula, e colocava cartões, com os numerais de zero a nove. Depois, ela passou a registrar também o nome da escola. Mais adiante, ampliou a sequência dos numerais e passou a registrá-los também no quadro. Depois, passou a escrever uma frase, envolvendo o nome da escola. Em alguns dias, junto com os alunos, fazia a contagem de meninos e meninas presentes e ausentes. Isso também era registrado no calendário. Outras vezes, eram os alunos que escreviam o alfabeto e os numerais. Os alunos copiavam do quadro tudo que era anotado por ela. O tempo destinado a essa atividade girava em torno de 40 minutos, tempo necessário para que todos os alunos copiassem tudo.

O estabelecimento da data do dia tinha a função de organizar a vida nessa comunidade e foi utilizado, pela professora, como uma estratégia para ampliar as possibilidades de aprendizagem dos alunos na medida em que eles eram levados a copiar mais coisas. De acordo com a professora:

Era mais com o objetivo de rotina mesmo. E deles se adequarem ao dia, ao calendário, ao mês, ao ano. Eaquela retomada todos os dias do alfabeto, dos numerais. Porque eu acredito que aquilo que você copia você memoriza, você grava. Era com esse objetivo, com esse intuito mesmo.

A partir do segundo semestre, a professora começou a desenvolver mais uma atividade de cópia: a cópia de textos curtos, com um maior número de palavras de um determinado grupo silábico. Esses textos 
eram retirados de coleções para alfabetização utilizadas por ela. Ela os registrava na lousa e os alunos copiavam no caderno. Em seguida, passava-se à leitura do texto. Nessa fase, ela solicitava a leitura silenciosa dos alunos: "Vocês já sabem juntar os pedacinhos... têm que pensar na cabecinha! Uma consoante e uma vogal". (Caderno de campo - 3 ago. 2010). E, depois, lia com eles, marcando no quadro sílaba por sílaba.

Podemos considerar essas atividades como típicas práticas de letramento escolar, conforme indicado por Rojo (2009, p. 60):

[...] a escola é a principal agência alfabetizadora e a alfabetização, enquanto processo de ensinar a ler e a escrever, é uma típica prática de letramento escolar, que apresenta as características sublinhadas por Lahire (1995): objetivar a linguagem em textos escritos, despertar a consciência para os fatos da linguagem, analisar a linguagem em sua composição por partes (frases, palavras, sílabas, letras).

A escola, ao desenvolver práticas como essas, tem tratado a linguagem escrita de modo abstrato e desconectado dos contextos sociais reais em que ela ocorre. Numa direção oposta, pesquisadores como Macedo (2001) e Soares (1998) têm defendido a alfabetização na perspectiva do letramento, o que implica ensinar não apenas o sistema de escrita, mas também as diferentes funções que esta ocupa na sociedade.

Quando essa professora selecionava um texto que tivesse mais palavras com uma determinada letra, com a qual ela estivesse trabalhando com os alunos, e encaminhava os alunos nesse processo de objetivação e compreensão da composição da linguagem em partes menores, ela estava possibilitando aos alunos a apropriação do sistema de escrita alfabético, no entanto, descontextualizando esse sistema na medida em que o texto em si não era objeto de trabalho em sala de aula.

Sobre essa atividade, a professora afirmou que:

A cópia do texto era mesmo aquela de... com a cópia do texto eles se... se evoluíam mais na escrita. Porque aquilo que você copia você memoriza mais. E a leitura era mesmo pra todos estarem... assim, a gente codificava, ia sílaba por sílaba, lendo junto, mesmo pra evoluir a leitura, na evolução da leitura mesmo. E pra que aqueles que não conseguiam ler sozinhos, com a minha ajuda e com a ajuda dos colegas, eles se habituariam a ler também. Muitos chegaram ao final do ano lendo, a maioria. (Entrevista) 
As duas falas da professora, apresentadas neste tópico, evidenciam a sua lógica no trabalho com a alfabetização. Para ela, o exercício de copiar repetidas vezes ainda é um caminho que pode contribuir com a aprendizagem dos alunos. Tanto a cópia diária do alfabeto, que integrava a atividade de cópia do calendário, quanto a cópia de pequenos textos eram utilizadas por ela com esse objetivo. Ao copiarem o texto com predominância de palavras de uma mesma "família", os alunos estariam fazendo um exercício de memorização daquele grupo estudado. Vimos que essa prática, questionada há mais de três décadas pelos estudos em alfabetização, especialmente o construtivismo (FERREIRO; TEBEROSKY, 1985) e os estudos sobre letramento (STREET, 1984; SOARES, 1998; 2008), ainda permanece de forma arraigada, mesmo num contexto de ampliação do EF cujas diretrizes apontam para uma lógica de alfabetização completamente distinta, uma alfabetização que considere a língua como prática social e não como uma técnica neutra.

\section{Leitura}

Observamos que a leitura possibilitada aos alunos era bastante limitada, uma vez que o foco predominante continuava no código escrito. A escolha dos textos a serem trabalhados e o objetivo da professora eram basicamente trabalhar um determinado conteúdo, por exemplo, tipos de moradia, ou introduzir o trabalho com uma determinada letra, conforme indicado por ela:

Começava pelo texto atrativo, depois eu identificava um texto que tinha mais uma família silábica. Vamos supor, se eu queria mais o objetivo da sílaba "ba", então eu conseguia arrumar um texto que tivesse mais o pedacinho "ba", pra criança identificar, circular onde tivesse o pedacinho "ba". Circular a palavra. E a partir dessa letrinha também gostava de dar a interpretação dessa letrinha. Mais focando na letra. Se tivesse um animalzinho no tex to com a letrinha. Por exemplo, um burro, se eu tivesse trabalhando a letrinha " $b$ ", a vaca, na letrinha " $v$ ". Sempre assim! Ou um animal que dava essa identificação do texto com o animal, pra eles socializarem melhor! (Entrevista).

Essas atividades de leitura começavam quando a professora distribuía uma folha mimeografada. Nela, os alunos encontravam uma letra do 
alfabeto nas suas quatro formas, um pequeno texto e um desenho. A professora começava apresentando aquela letra. Fazia uma retomada da última letra trabalhada, retomava a sequência do alfabeto, quais são as vogais, quais são as consoantes e chegava à letra em questão. Junto com os alunos, ela ia formando as sílabas daquela letra. Enfatizava a união daquela consoante com cada vogal e registrava na lousa. Formavase, assim, a família silábica. Em seguida, ela orientava uma atividade de identificação: os alunos deviam ler o texto silenciosamente e tentar identificar nele a letra que estava sendo apresentada.

No início do ano, os alunos identificavam apenas a letra trabalhada no texto. Depois, passaram a identificar palavras começadas com aquela letra. Num outro texto, a professora dava sequência ao seu trabalho com a leitura, em que os alunos eram solicitados a ouvir, atentamente, a leitura feita em voz alta por ela. Ela fazia isso duas vezes ou mais, com o objetivo de levar os alunos a memorizarem certas informações do texto. Em seguida, passava para as perguntas. A professora lia cada uma, pausadamente, e os alunos respondiam oralmente a partir do que ouviram e entenderam da leitura feita por ela. A professora registrava no quadro a resposta da questão e os alunos copiavam em suas folhas.

Tais práticas evidenciam a escolarização da escrita numa perspectiva que compreende a leitura apenas como um processo de decodificação. Diferentemente, durante as observações desenvolvidas na turma, identificamos o desenvolvimento de um projeto intitulado Ciranda da leitura. Esse projeto ocorria em dois dias da semana: na sexta-feira, quando os alunos levavam um livro para a casa, e na segunda-feira, quando devolviam esse livro e recontavam a história. Importante ressaltar que os alunos, em vez de levarem, junto com o livro, a tradicional ficha de leitura usada nas escolas (ALMEIDA; MACEDO, 2007), apenas tinham como tarefa completar uma tabela com o título do livro, autor, ilustrador e editora. Questionada sobre isso, a professora destacou que a opção por não enviar ficha de leitura foi uma decisão tomada coletivamente com a coordenadora pedagógica da escola e se deve ao fato de não ter sido uma boa experiência em anos anteriores. Segundo ela, a ficha se torna uma atividade repetitiva e cansativa para os alunos. 
Repetição essa não questionada por ela quando se trata das atividades de ensino do código, evidenciando a sua dificuldade de articular texto, leitura e o ensino do código escrito.

O livro literário era usado pela professora também em outros momentos da sua rotina. Observamos esse uso em alguns dias, e não diariamente, mas era com o objetivo que ela aponta:

Todos os dias eu lia uma historinha e depois pedia o reconto dessa historinha. O que eles entenderam, fazia umas perguntas do livrinho, isso todos os dias. Justamente depois do recreio pra eles darem uma acalmada, eu lia uma história, um livrinho. Todos os dias! Depois do recreio, eles davam uma acalmadinha, que eles adoram ouvir história e o reconto do livro também é muito importante, pra ver se eles entenderam mesmo, se prestaram atenção no que eu estava lendo. (Entrevista)

Notamos, nessa sala de aula, poucas possibilidades de leitura de textos de forma articulada ao processo de alfabetização. Conforme indicado, os alunos puderam ler textos curtos, não literários, mas textos escritos pela própria professora ou retirado das coleções de alfabetização, com o objetivo claro do ensino do sistema de escrita alfabético. Nesses textos, os alunos precisavam identificar letras, palavras ou sílabas de um determinado grupo silábico. Puderam, sim, levar livros literários para casa, fazer a leitura com a família e recontá-lo na sala de aula, momento em que a leitura com o objetivo de fruição e prazer (PAULINO et al., 2001), era minimamente contemplada. Observa-se, portanto, uma tensão entre o ensino do código escrito e o trabalho com textos reais de função social, como o texto literário.

No primeiro caso, os alunos precisam ler textos curtos, extraídos de materiais didáticos, para identificar palavras ou letras, ou ainda responder a questões. No segundo, a professora possibilita que livro literário mesmo não sendo lido pelos alunos em sala de aula, possa ser lido em casa sem a cobrança de fichas de leitura tão presentes nas práticas de escolarização da leitura literária. Além disso, os alunos sabiam que, na segunda-feira, alguns deles seriam selecionados para o reconto, o que, em alguma medida, reforça o caráter de sistematização dessa leitura, evidenciando que leitura totalmente livre de objetivos pedagógicos não ocorre facilmente na escola. 


\section{Outras atividades de sistematização do código}

Normalmente, os alunos eram solicitados a formar ou completar palavras com letras e sílabas faltosas, fazer cruzadinhas e caça-palavras, escrever palavras ditadas ou a partir de figuras e separar palavras em sílabas, sempre de um determinado grupo silábico, que havia sido apresentado pelas atividades de leitura, descritas anteriormente.

Depois dessas atividades, era costume da professora reescrever as palavras no quadro e fazer com os alunos uma "sistematização" daquele grupo silábico. Depois do registro, os alunos eram convidados a fazer, coletivamente, a leitura das palavras. A professora ia marcando um traço debaixo das sílabas de cada palavra e os alunos iam soletrando.

A complexidade que envolve o processo de alfabetização tem tornado essa prática um desafio para docentes que atuam com turmas de crianças de seis, sete e oito anos. Acreditamos que, para uma boa prática alfabetizadora, é necessário que o professor tenha conhecimento teórico sobre a linguagem escrita e sobre as formas pelas quais as crianças se apropriam da natureza alfabética do nosso sistema de escrita. Destacamos, na rotina observada, a opção pelo trabalho sistemático com o foco restrito na codificação e decodificação de palavras, mesmo a professora afirmando partir de um texto, conforme podemos observar na sua própria fala:

A gente começa na alfabetização com as vogais. Você introduz as vogais pras crianças, através de quê? As vogais eu colo num cartãozinho com as letras, com música. Depois que elas memorizaram bem as vogais ai nós partimos pras consoantes. Aí a gente trabalha o quê? Cada letra do alfabeto que juntando uma consoante com uma vogal ele consegue formar uma sílaba. Através de textos daquela letrinha do alfabeto que você tá trabalhando. A antiga família, né. A família silábica. Porque agora você não pode mais trabalhar o ba-be-bi-bo-bu-, só que você trabalha de uma outra forma, não com aquela decoração da criança, através de cartilhas, mas através dela perceber essas sílabas, num texto, numa trava-língua, em parlenda. (Entrevista)

A fala da professora evidencia a forma com que ela se apropriou de um discurso circulante nas três últimas décadas que contestou o uso de cartilhas no processo de ensino-aprendizagem da leitura e 
da escrita: "porque agora você não pode mais trabalhar o ba-be-bi-bo-bu" (Entrevista); discurso esse muitas vezes confundido com a negação da importância da análise silábica na construção da escrita. A professora demonstra reconhecer a importância do trabalho com a sílaba, porém o faz utilizando-se das mesmas estratégias propostas pelas cartilhas tradicionais de alfabetização, banidas das escolas pelo Programa Nacional de Livro Didático (PNLD).

Observamos que a opção que ela faz é pelos métodos sintéticos, presentes nas cartilhas, nos quais as atividades de ensino são centradas na memorização das partes que compõem as palavras, como as sílabas e as letras. As atividades de cruzadinhas e caça-palavras, que poderiam indicar a opção por textos de circulação social, está vinculada à ideia de aquisição do código. Em nenhum momento, a professora dá indícios de que se utilizava desses textos para uma aproximação com práticas reais de uso da leitura e da escrita, mas, sim, para trabalhar palavras de um determinado grupo silábico. Para Miranda (2008, p. 142):

[...] nessa perspectiva, a aprendizagem é considerada como resultado do acúmulo de informações e não como reorganização e reestruturação dos conhecimentos disponíveis. Da mesma forma, os interesses e a realidade cognitiva, emocional e social dos alunos são desconsiderados, como se eles não tivessem noções e hipóteses acerca do funcionamento da língua.

\section{Considerações finais}

Ao longo deste texto, defendemos a nossa concepção de que a alfabetização precisa acontecer na perspectiva do letramento. Levar os alunos a dominarem as convenções do nosso sistema de escrita não é suficiente para garantir a eles que se alfabetizem e se letrem ao mesmo tempo.

Observamos, nessa prática, uma tentativa da professora de possibilitar aos alunos se apropriarem do sistema de escrita alfabético a partir de textos, o que poderia ser considerado um avanço na perspectiva defendida por esta pesquisa. Contudo, os textos escritos pela própria professora ou retirados de cartilhas e são utilizados apenas como pretexto para o ensino sistemático do código escrito. Os alunos leem textos curtos, que às vezes já sabem de memória, ou a letra de uma música infantil 
para identificarem nele letras ou palavras de um determinado grupo silábico. Não observamos uma preocupação com a variedade de gêneros textuais, tão defendida por Leal, Albuquerque e Morais (2007, p. 71): "Qualquer cidadão lê e escreve cumprindo finalidades diversas e reais. Precisamos garantir esse mesmo princípio ao iniciarmos os estudantes no mundo da escrita".

Leal, Albuquerque e Morais (2007) defendem ainda que a escola, responsável pelo ensino da leitura e da escrita, tem como uma de suas funções reduzir as diferenças sociais existentes entre crianças que têm acesso à leitura desde muito cedo e crianças que não participam de uma cultura letrada. Essa redução só aconteceria por meio da vivência diária de práticas reais de leitura e produção de textos diversificados, que não foi observada em nenhum momento nessa sala de aula.

Ao contrário, o que verificamos foram atividades como: cópia, repetição de palavras soltas, decodificação de sílaba por sílaba. Ou seja, a concepção de alfabetização presente nessa prática se vincula a uma visão da escrita apenas como um código de transcrição das unidades sonoras em unidades gráficas. Uma concepção que se pauta em métodos sintéticos para o ensino da língua, uma concepção que se vincula à concepção de letramento autônomo, questionada por Street (1984).

Por fim, sabemos que muito se tem falado sobre a necessidade de se reverterem resultados negativos no processo inicial de escolarização e do reiterado fracasso da escola brasileira em alfabetizar. Antes de qualquer coisa, é preciso assumir a complexidade desse fenômeno. Questões relativas ao processo de alfabetização e letramento de crianças no início da escolarização obrigatória são sempre questões complexas e que podem ser analisadas sob diferentes perspectivas. Entretanto, não podemos deixar de denunciar o processo de "desaprendizagem" das verdadeiras funções da escrita que a escola impõe, sobretudo às crianças das camadas populares, que, com o EF de nove anos, têm chegado, em maior número, às escolas brasileiras; e, simultaneamente, o processo de "aprendizagem de uma escrita que nega a funcionalidade dessa forma de interlocução, nega a subjetividade de autor e leitor e, sobretudo, nega o direito de usar a escrita para dizer a própria palavra" (SOARES, 
2008, p. 81), quando privilegia práticas como as que foram reveladas no nosso estudo.

Compreendemos, assim, que nem tudo que acontece na sala de aula é da vontade do professor, mas depende do contexto e do tempo histórico do qual ele faz parte. Esperamos, com este estudo de caso, reforçar a necessidade de mais discussões com os professores em torno dos referenciais teórico-metodológicos que estão na base da política de ampliação do EF, para que se garantam condições adequadas de trabalho com esses referenciais no sentido de que esse ano a mais possa representar de fato um salto na qualidade da educação no Brasil. 


\section{Referências}

ALMEIDA, A. C.; MACEDO, M. do S. A. N. O papel do livro didático e de outros impressos nas práticas de alfabetização no primeiro ciclo. In: PEREIRA, L. H.; OLIVEIRA, W. C. Práticas educativas: discursos e produção de saberes. Rio de Janeiro: E-Papers, 2007. p. 7-30.

ARAÚJO, R. de C. Construindo sentidos para a inclusão das crianças de 6 anos de idade no Ensino fundamental de 9 anos: um diálogo com professores. 2008. 149 f. Dissertação (Mestrado em Educação) - Faculdade de Educação, Universidade Federal de Juiz de Fora, Juiz de Fora, 2008.

BONFIM, P. V. A criança de nove anos no EF: uni duni tê... Corporeidade e Ludicidade - mais que uma rima, um porquê. 2010. 130 f. Dissertação (Mestrado em Educação) - Faculdade de Educação, Universidade Federal de São João del-Rei, São João del-Rei, 2010.

BRASIL. Constituição Federal. Brasília, 1988.

BRASIL. Lei n. 11.274, 6 de fevereiro de 2006. Altera a redação dos art. 29, 30, 32 e 87 da BRASIL. Lei n. 9.394, de 20 de dezembro de 1996. Estabelece as diretrizes e bases da educação nacional, dispondo sobre a duração de 9 (nove) anos para o ensino fundamental, com matrícula obrigatória a partir dos 6 (seis) anos de idade. Diário Oficial da União: Brasília, 7 fev. 2006.

BRASIL. Ministério da Educação. Secretaria de Educação Básica. Ensino fundamental de nove anos: orientações para a inclusão da criança de seis anos de idade. Brasília, 2007.

CASTANHEIRA, M. L.; GREEN, J. L.; DIXON, C. N. Práticas de letramento em sala de aula: uma análise de ações letradas como construção social. Revista Portuguesa de Educação, Portugal, v. 20, n. 2, p. 7-38, 2007. 
CRUVINEL, C. L. C. G. Políticas para educação obrigatória: o ensino fundamental com nove anos de duração. 2009. 147 f. Dissertação (Mestrado em Educação) - Faculdade de Educação, Universidade de Campinas, Campinas, 2009.

DANTAS, A. G. Ensino Fundamental de nove anos no Distrito Federal: reflexões sobre a inserção de crianças de 6 anos no ensino público e atuação docente. 2009. 152 f. Dissertação (Mestrado em Educação) Faculdade de Educação, Universidade de Brasília, Brasília, 2009.

FERREIRO, E.; TEBEROSKY, A. A psicogênese da língua escrita. Porto Alegre: Artes medicas, 1985.

FLASH, S. de F. Direito à educação e ampliação da escolaridade obrigatória em Ponta Grossa (2001- 2008). 2009. 170 f. Dissertação (Mestrado em Educação) - Centro de Educação, Universidade Federal de São Carlos, São Carlos, 2009.

GREEN, J.; DIXON, C. N.; ZAHARLICH, A. A etnografia como uma lógica de investigação. Educação em Revista, Belo Horizonte, v. 42. p. 13-79, dez. 2005.

LEAL, T. F.; ALBUQUERQUE, E. B. C.; MORAIS, A. G. Letramento e Alfabetização: pensando a prática pedagógica. In: BEAUCHAMP, J.; PAGEL, S. D.; NASCIMENTO, A. R. Ensino Fundamental de nove anos orientações para a inclusão da criança de seis anos de idade. Brasília: Ministério da Educação, Secretaria da Educação Básica, 2007. p. 97-108.

MACEDO, M. do S. A. N. Desafios da alfabetização na perspectiva do letramento. Revista Presença Pedagógica, Belo Horizonte, v. 7, n. 37, p. 17-24, jan./fev. 2001.

MACEDO, M. do S. A. N. Interações nas práticas de letramento em sala de aula e o uso do livro didático e da metodologia de projetos. São Paulo: 
Martins Fontes, 2005.

MACEDO, M. do S. A. N. Letramento escolar como um espaço de tensões: um estudo de caso de uma turma de primeiro ciclo. In: COLÓQUIO INTERNACIONAL SOBRE LETRAMENTO E CULTURA ESCRITA, 3. 2010. Anais... Belo Horizonte, 2010.

MIRANDA, M. I. Epistemologia genética, alfabetização e letramento. Educ. e Filos., Uberlândia, v. 22, n. 44, p. 141-158, jul./dez. 2008.

MORTATTI, M. do R. L. Educação e letramento. São Paulo: Editora Unesp, 2004.

PAULINO, G. et al. (Org.). Tipos de textos, modos de leitura. Belo Horizonte: Formato Editorial, 2001. (Coleção Educador em Formação).

ROJO, R. H. R. Letramentos múltiplos, escola e inclusão social. São Paulo: Parábola Editorial, 2009.

SANTOS, L. L. de C. P.; VIEIRA, L. M. F. “Agora seu filho entra mais cedo na escola": a criança de seis anos no Ensino Fundamental de 9 anos de Minas Gerais. Revista Educação e Sociedade, Campinas, v. 27. n. 96, p. 775-796, out. 2006.

SOARES, M. Letramento: um tema em três gêneros. Belo Horizonte: Autêntica, 1998.

SOARES, M. Alfabetização e letramento. 5. ed. São Paulo: Contexto, 2008.

STREET, B. Literacy in theory and pratic. Cambridge: University Cambridge. 1984.

STREET, B. Cross-cultural Approaches to Lyteracy. New York: Cambridge University Press, 1993. 
STREET, B. (Ed.). Literacy and development: ethnographic perspectives. Londres/Nova York: Routledge/Taylor \& Francis Group, 2001.

STREET, B. What's "new" in New Literacy Studies? Critical Approaches to Literacy in Theory and Practice. Current Issues in Comparative Education, Estados Unidos, v. 5, n. 2, p. 77-91. Columbia: Teachers College, Columbia University, 2003.

Recebido: 05/12/2012 Aprovado: 14/11/2013 